\title{
THE CHOICE OF COMPACT FLUORESCENT LIGHT BULBS USING THE METHOD OF SAW AND CP
}

\author{
MSc. Ivana Zdravković, "Radoje Domanović” School, elektrokontakt.vr@ gmail.com \\ Prof. Momčilo Vujičić PhD, Faculty of Engineering, Čačak, momcilo.vujicic@ftn.kg.ac.rs
}

\begin{abstract}
Multi-criteria analysis allows making decision in conflict conditions, when there are multiple alternatives and criteria, some of which should be maximized and some minimized. Therefore, in solving multicriteria tasks should use flexible instruments, by character of pure mathematical optimization techniques. The paper discusses choice of compact fluorescent light bulbs through multi-criteria decision-making methods, specifically in this case, the method of SAW and the method compromise programming (CP).
\end{abstract}

Keywords: multi-criteria analysis, weight criteria, $S A W, C P$

\section{INTRODUCTION}

Decision-making and the selection of optimal solutions has always represented one of the biggest challenges, both in science, and in the real life. Today, with the development of scientific disciplines, such as various types of research, management, computer science and statistics, making optimal decisions for a given problem are greatly facilitated.

In order to deliver a good decision in solving a task or problem, it is necessary to specify an alternative definition of the relevant criteria. It is also necessary to define the weights of each criterion, and the importance of each criterion relative to the other. Multi-criteria analysis allows making decision in conflict conditions, when there are multiple alternatives and criteria, some of which should be maximized and some minimized. Therefore, in solving multi criteria tasks need use flexible instruments by character of mathematical techniques pure optimization.

Alternatives are evaluated separately by the each criterion based on the exact set of parameters or subjective evaluation. The way to express that evaluation depends on the chosen method that is used to solve the problem. Today there are several methods of multi-criteria decision making (SAW, CP, etc.) and depending on the method used, is obtained a solution:

- Rank alternatives

- Best alternative

- A set of alternatives that meet certain conditions.

\section{COMPACT FLUORESCENT LAMPS}

Compact fluorescent lamps (CFL) bulbs are gas discharge in which the invisible UV radiation generated by the collision of mercury atoms and electrons emitted from the electrodes into the bulb is converted into visible radiation (ie light) with phosphorus. Unlike fluorescent lamps, they do not need any additional components such as the starter and ballast. They can be connected directly to the network. Compact fluorescent lamps have a luminous efficacy of $50-100 \mathrm{~lm} / \mathrm{W}$, while incandescent bulbs have $10-22 \mathrm{~lm} / \mathrm{W}$. This means that compact fluorescent light bulbs convert electrical energy into light five times faster than incandescent lights. They have a long life span, between 3,000 and 15,000 hours, whereas incandescent lamps have an average life of 1,000 hours. They have a wide range of colors and shapes. Easy to install and do not need extra components such as starter and ballast. They are not affected much voltage fluctuation in the distribution network. They do not emit a lot of heat while operating. The main advantage of using compact fluorescent bulbs over conventional incandescent lamps reflected in significant fuel consumption and, accordingly, these bulbs known as the "energy saving" bulbs. In particular, this means that energy saving light bulbs use less electricity for the same amount of light produced. However, while saving light 
bulbs use less electricity while using, on the other hand, more energy is required to produce them. Energy saving bulbs have several times longer lifespan. There are several problems with the design of efficient light bulbs. One of the principal problems is that the amount of light emitted by these lamps is proportional to the size of the phosphor surface, which means are the bulbs with a higher power, greater than equivalent incandescent bulbs. Very often, this type of light bulbs does not fit in the chandelier, where we had a bulb. The inability to control the light output is also a problem that is typical for compact fluorescent lamps. Only a small number of specific types of these bulbs have this opportunity. Full brightness level of energy saving light bulbs is achieved only after a relatively long period of time (up to 3 minutes). At the beginning of the light level can be even half from the normal a full level._For example, a bulb needs only about 0.1 seconds to reach full brightness. Energy gaps in the blue region of the spectrum fluorescent source (even warm white light) influence on the hormonal imbalance in your body. Since the secretion of melatonin and serotonin, hormones that regulate a person's circadian rhythm (night-day biological clock) depend on signals from the eye receptor for blue light. Ultraviolet radiation is harmful to humans if it is regularly exposed to long periods of time. In the EU, compact fluorescent bulbs subject to the directive scheme for waste electrical and electronic equipment. (Waste Electrical and Electronic Equipment Directive (WEEE)). The retail price includes the amount of recycling, with it, the manufacturers and importers are obliged to collected and recycled used light bulbs.

\section{DETERMINATION WEIGHT OF CRITERIA}

Due to the fact that weight criteria, can significantly affect the outcome of the decision process, It is clear that special attention must be paid to objectivity weight of criteria, which unfortunately is not always present in the solution of practical problems. Knowing the true meaning of the criteria is essential for a proper application of methods and models.
In general, most approaches to assess weight of criteria can be divided into subjective and objective.

Subjective approaches are based on the determination of weights of criteria based on information provided by the decision makers or experts involved in the decision-making process. Objective approaches are based on the determination of criteria weights on the basis of information contained in the decision matrix by using various mathematical models. Their main characteristic is to disregard the opinion of the decision maker.

3.1. Methods for objective approach to determining weights of criteria

Of method of objective access determining weights of criteria, are considered are variants of value with regard to a set of criteria, obtained the information about the values weights of criteria that focus on the analysis of decision matrix. The best-known objective methods of determining the weight of the criteria are: Entropy method, method CRITIC, and methods FANMA.

\subsubsection{Entropy method}

This method of evaluation weights of criteria based on Shannon's concept entropic of reviews the information contained in the decision matrix (Shannon and Weaver, 1947). $\mathrm{He}$ is reduced to measurement vagueness in the information that emitted by the matrix and directly generates weights of criteria, by mutual contrast individual ratings alternatives for each criterion and then at the same time for all the criteria. ${ }^{1}$

\footnotetext{
${ }^{1}$ Srđević B.,, Medeiros Y.D.P., Faria, A.S., Schaer, M., Objective evaluation performance of criteria system of reservoir, Waterpower engineering, 35, 163-176, Novi Sad, 2003.
} 


\subsubsection{Method CRITIC}

This method is a method for determining the value of objective weights of criteria including the intensity of contrast and conflict that is included in the structure of the decision problem. It belongs to the class of correlation methods and is based on an analytical examination of decision matrix to determine the information contained in the criteria by which variants are evaluated. ${ }^{2}$

\subsubsection{Method FANMA}

The concept of using the principles of distance from the ideal point or early weight normalization is a concept that applies to the determination weights of criteria method FANMA. $^{3}$

\section{METHODS MULTIPLE CRITERIA DECISION-MAKING}

\subsection{SAW method}

SAW method (Simple Additive Weighting Method $)^{4}$ is a method simple additive weight and is considered to be one of the best known and most common methods in the field of multi-criteria decision making.

Besides that SAW method provides a simple and convenient alternative to the ranking procedure, results obtained its implementation does not differ from the results obtained by some so-called advanced methods. Directly is an applicable to the decision matrix and consists of three steps:

- The normalization of decision matrix;

- Multiply the normalized matrix the weighted coefficients, and

2 Diakoulaki, D., Mavrotas, G., Papayannakis L., Determining objective weights in multiple criteria problems: the CRITIC method. Computers and Operations Research, 22, 763770, 1995.

3 Srđević B., Unbiased assessment of important criteria in multicriteria optimization, Waterpower engineering, 37, 53-58, 2005.

4 Hwang C.L., Yoon K.S.: Multiple attribute decision making: methods and applications, Springer, Berlin, 1981.
- Addition of "difficult" parameters for each alternative.

The method is particularly suitable when the criteria are the same or similar nature. The decision maker should assign to each criterion relative weight or weighted coefficient $\left(\mathrm{w}_{\mathrm{k}}, \mathrm{k}\right.$ $=1,2, \ldots, \mathrm{m})$. Best value alternative is one where the sum of "difficult" parameter has a maximum value. Normalization of alternatives with respect to all criteria is performed on the basis of formula 1 and 2 .

If it comes maximized criteria:

$$
r_{i j}=\frac{x_{i j}-x_{r}^{* *}}{x_{j}^{*}-x_{j}^{* *}}
$$

While in minimized used:

$$
r_{i j}=\frac{x_{i}^{*}-x_{i j}}{x_{j}^{*}-x_{j}^{* *}}
$$

Where $x_{j}^{*}$ is the best value for all

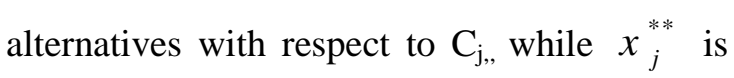
the worst value. When is done normalization criteria and formed a new matrix, it is multiplied by the corresponding weighted coefficients.

The values of alternatives are obtained by adding the results of a new matrix.

$$
S_{i}=\sum_{j=1}^{m} w_{j} \cdot r_{i j}
$$

Best value alternative is one where $S_{i}$ has the highest value. 


\subsection{Method CP - Compromise Programming}

Compromise programming method is based on minimizing the distance from the reference point, usually the ideal point. This actually means that this method ranks alternatives according to closeness to certain ideal values of criteria. Minimization proximity to the ideal values surrogate is standard procedure maximizing the criterion functions. As the best, $\mathrm{CP}$ method defines the alternative with the smallest distance from the ideal solution in the set of possible solutions. In addition, with $\mathrm{CP}$ method is included and weight as a measure of the importance of the criteria.

To measure the distance points can be used different metrics. Distance measure is a family of Lp-metric given in: ${ }^{5}$

$$
L_{p}(i)=\left[\sum_{j=1}^{m} w_{j}^{p}\left|\frac{r_{j}^{*}-r_{i j}}{r_{j}^{*}-r_{j}^{* *}}\right|^{p}\right]^{1 / p}
$$

Where are:

$L_{p}(i)$ - designation for $L_{p}$ metric alternatives $A_{i}$;

$r_{i j}$ - rating alternatives $A_{i}$ in relation to the criteria $\mathrm{C}_{j}$;

$r_{j}^{*}, r_{j}^{* *}$ - best and worst rating value in a set of alternatives for the criteria $\mathrm{C}_{j}$;

$p$ - parameter preferences of decision makers in the evaluation;

$m$ - number of criteria; $\mathrm{n}$ - number of alternatives.

The alternative with minimal Lp-metric is considered to the best, and the ranking is done by increasing Lp-metric.

The parameter $p$, indirectly shows preference of balancing criteria $(\mathrm{p}=1)$, normal use of the effect of squaring errors $(p=2)$, or seeking absolutely dominant solution $(\mathrm{p}=)$. If we

\footnotetext{
${ }^{5}$ Zeleny, M. (1982) Multiple citeria decision making, McGraw-Hill Book Company, New York
}

allow mutually compensating criteria $\mathrm{p}$ must be 1 , reduce the marginal value of the objective function, $p$ must be greater than 1. A specific case is, when important only absolutely best alternative, and then $p$ takes an infinite value, and this case is also called Cebus metric or min-max criterion. In each of these cases, target function of the optimization problem is transformed are into a different form.

\section{ILLUSTRATIVE EXAMPLES}

As a basis for the application methods of multi-criteria decision-making, in the selection of compact fluorescent light bulbs, given had initial data of bulbs (Table 1). 
Table 1 Data on light bulbs

\begin{tabular}{|l|l|l|l|l|l|}
\hline Criterion & $\mathrm{f}_{1}$ & $\mathrm{f}_{2}$ & $\mathrm{f}_{3}$ & $\mathrm{f}_{4}$ & $\mathrm{f}_{5}$ \\
\hline Bulbs & Brightness & $\begin{array}{l}\text { Active power } \\
(\mathrm{W})-\max )\end{array}$ & $\begin{array}{l}\text { Lifespan } \\
(\mathrm{h})-\max \end{array}$ & $\begin{array}{l}\text { Cost price } \\
(\mathrm{CSD}) \\
\min \end{array}$ & $\begin{array}{l}\text { Apparent } \\
\text { power } \\
(\mathrm{VA})-\text { min }\end{array}$ \\
\hline $\mathrm{a}_{1}$ & 195 & 20.6104 & 8000 & 400 & 34.415 \\
\hline $\mathrm{a}_{2}$ & 94 & 20.8448 & 6000 & 300 & 34.045 \\
\hline $\mathrm{a}_{3}$ & 153 & 18.0754 & 8000 & 350 & 30.327 \\
\hline $\mathrm{a}_{4}$ & 170 & 19.8181 & 8000 & 600 & 32.076 \\
\hline $\mathrm{a}_{5}$ & 110 & 21.8495 & 6000 & 380 & 34.343 \\
\hline $\mathrm{a}_{6}$ & 75 & 17.3137 & 8000 & 335 & 30.611 \\
\hline $\mathrm{a}_{7}$ & 192 & 17.2853 & 8000 & 849 & 28.112 \\
\hline $\mathrm{a}_{8}$ & 187 & 19.658 & 8000 & 418 & 33.184 \\
\hline $\mathrm{a}_{9}$ & 224 & 17.8487 & 12000 & 375 & 29.422 \\
\hline $\mathrm{a}_{10}$ & 19 & 6.9427 & 8000 & 150 & 12.282 \\
\hline $\mathrm{a}_{11}$ & 194 & 21.8663 & 8000 & 300 & 37.590 \\
\hline
\end{tabular}

I) Results of the analysis method SAW and CP for selection of compact fluorescent light bulbs based on five criteria $\left(f_{1}-\right.$ Brightness, $f_{2}-$ Active power, $f_{3}-$ Lifespan, $f_{4}-$ Cost price, $f_{5}-$ Apparent power), using the weights of criteria Entropy, CRITIC и FANMA:

Weighting factors:

\begin{tabular}{|l|l|l|l|l|l|}
\hline & $\mathrm{w}_{1}$ & $\mathrm{w}_{2}$ & $\mathrm{w}_{3}$ & $\mathrm{w}_{4}$ & $\mathrm{w}_{5}$ \\
\hline Entropy & 0.407 & 0.109 & 0.062 & 0.322 & 0.100 \\
\hline CRITIC & 0.155 & 0.183 & 0.277 & 0.211 & 0.174 \\
\hline FANMA & 0.296 & 0.104 & 0.135 & 0.349 & 0.116 \\
\hline
\end{tabular}


(JPMNT) Journal of Process Management - New Technologies, International

Vol. 1, No.4, 2013.

Comparison of results of multi-criteria decision making methods:

\begin{tabular}{|c|c|c|c|c|c|c|c|c|c|c|c|c|}
\hline \multirow{2}{*}{ Method } & \multirow{2}{*}{$\begin{array}{l}\text { Weight of } \\
\text { criterion }\end{array}$} & \multicolumn{11}{|c|}{ Bulbs } \\
\hline & & $\mathbf{A}_{1}$ & $\mathbf{A}_{2}$ & $\mathbf{A}_{3}$ & $\mathbf{A}_{4}$ & $\mathbf{A}_{5}$ & $\mathbf{A}_{6}$ & $\mathbf{A}_{7}$ & $\mathbf{A}_{8}$ & $\mathbf{A}_{9}$ & $\mathbf{A}_{10}$ & $\mathbf{A}_{11}$ \\
\hline \multirow{3}{*}{ SAW } & Entropy & 3 & 9 & 5 & 7 & 10 & 11 & 8 & 4 & $\underline{1}$ & 6 & 2 \\
\hline & CRITIC & 6 & 10 & 3 & 8 & 11 & 7 & 9 & 4 & $\underline{1}$ & 2 & 5 \\
\hline & FANMA & 4 & 9 & 6 & 8 & 10 & 7 & 11 & 5 & $\underline{1}$ & 3 & 2 \\
\hline \multirow{3}{*}{$\mathbf{C P}$} & Entropy & 3 & 8 & 5 & 6 & 7 & 9 & 10 & 4 & $\underline{1}$ & 11 & 2 \\
\hline & CRITIC & 6 & 10 & 3 & 7 & 11 & 4 & 9 & 5 & $\underline{1}$ & 2 & 8 \\
\hline & FANMA & 4 & 7 & 2 & 9 & 8 & 6 & 11 & 5 & $\underline{1}$ & 10 & 3 \\
\hline
\end{tabular}

II) The results after the tests carried out using the following four criteria $\left(f_{1}-\right.$ Brightness, $f_{2}-$ Active power, $\mathrm{f}_{3}$ - Apparent power, $\mathrm{f}_{4}$ - Cost price):

Weighting factors:

\begin{tabular}{|l|l|l|l|l|}
\hline & $\mathrm{w}_{1}$ & $\mathrm{w}_{2}$ & $\mathrm{w}_{3}$ & $\mathrm{w}_{4}$ \\
\hline Entropy & 0.407 & 0.109 & 0.062 & 0.322 \\
\hline CRITIC & 0.155371 & 0.182779 & 0.276690 & 0.211101 \\
\hline FANMA & 0.181 & 0.063 & 0.243 & 0.214 \\
\hline
\end{tabular}

Comparison of the analysis methods SAW and CP using four criteria:

\begin{tabular}{|c|c|c|c|c|c|c|c|c|c|c|c|c|}
\hline \multirow[t]{2}{*}{ Method } & \multirow{2}{*}{$\begin{array}{l}\text { Weight of } \\
\text { criterion }\end{array}$} & \multicolumn{11}{|c|}{ Bulbs } \\
\hline & & $\mathbf{A}_{1}$ & $\mathbf{A}_{2}$ & $\mathbf{A}_{3}$ & $\mathbf{A}_{4}$ & $\mathbf{A}_{5}$ & $\mathbf{A}_{6}$ & $\mathbf{A}_{7}$ & $\mathbf{A}_{8}$ & $\mathbf{A}_{9}$ & $\mathbf{A}_{10}$ & $\mathbf{A}_{11}$ \\
\hline \multirow[t]{3}{*}{$\underline{\text { SAW }}$} & Entropy & 3 & 8 & 5 & 6 & 10 & 11 & 9 & 4 & $\underline{1}$ & 7 & 2 \\
\hline & CRITIC & 6 & 10 & 3 & 8 & 11 & 7 & 9 & 5 & $\underline{1}$ & 2 & 4 \\
\hline & FANMA & 3 & 8 & 5 & 7 & 10 & 9 & 11 & 4 & $\underline{1}$ & 6 & 2 \\
\hline \multirow[t]{3}{*}{$\underline{\mathbf{C P}}$} & Entropy & 3 & 8 & 5 & 6 & 7 & 9 & 10 & 4 & $\underline{1}$ & 11 & 2 \\
\hline & CRITIC & 6 & 10 & 3 & 8 & 11 & 5 & 9 & 4 & $\underline{1}$ & 2 & 7 \\
\hline & FANMA & 3 & 7 & 4 & 9 & 8 & 6 & 11 & 5 & $\underline{1}$ & 10 & 2 \\
\hline
\end{tabular}

III) The results after the tests carried out using the following four criteria $\left(f_{1}-\right.$ Brightness, $f_{2}-$ Lifespan, $\mathrm{f}_{3}-$ Cost price, $\mathrm{f}_{4}-$ Apparent power): 
Weighting factors:

\begin{tabular}{|l|l|l|l|l|}
\hline & $\mathrm{w}_{1}$ & $\mathrm{w}_{2}$ & $\mathrm{w}_{3}$ & $\mathrm{w}_{4}$ \\
\hline Entropy & 0.407 & 0.062 & 0.322 & 0.100 \\
\hline Critic & 0.155371 & 0.276690 & 0.211101 & 0.174057 \\
\hline FANMA & 0.181 & 0.243 & 0.214 & 0.299 \\
\hline
\end{tabular}

Comparison of the analysis methods SAW and CP using four criteria:

\begin{tabular}{|c|c|c|c|c|c|c|c|c|c|c|c|c|}
\hline \multirow[t]{2}{*}{ Method } & \multirow{2}{*}{$\begin{array}{l}\text { Weight of } \\
\text { criterion }\end{array}$} & \multicolumn{11}{|c|}{ Bulbs } \\
\hline & & $\overline{A_{1}}$ & $\overline{A_{2}}$ & $\mathbf{A}$ & $\mathbf{A}_{4}$ & $\mathbf{A}_{5}$ & $\overline{A_{6}}$ & $\overline{A_{7}}$ & $\overline{A_{8}}$ & $\mathbf{A 9}_{9}$ & $\mathbf{A}_{10}$ & $\mathbf{A}_{11}$ \\
\hline \multirow[t]{3}{*}{$\underline{\text { SAW }}$} & Entropy & 3 & 7 & 5 & 6 & 9 & 11 & 8 & 4 & $\underline{1}$ & 10 & 2 \\
\hline & CRITIC & 5 & 10 & 3 & 8 & 11 & 7 & 9 & 6 & $\underline{1}$ & 2 & 4 \\
\hline & FANMA & 3 & 8 & 5 & 7 & 10 & 9 & 11 & 4 & $\underline{1}$ & 6 & 2 \\
\hline \multirow[t]{3}{*}{$\underline{\mathrm{CP}}$} & Entropy & 3 & 8 & 5 & 6 & 7 & 9 & 10 & 4 & $\underline{1}$ & 11 & 2 \\
\hline & CRITIC & 6 & 10 & 3 & 7 & 11 & 4 & 9 & 5 & $\underline{1}$ & 2 & 8 \\
\hline & FANMA & 4 & 7 & 3 & 9 & 6 & 8 & 11 & 5 & $\underline{1}$ & 10 & 2 \\
\hline
\end{tabular}

IV) The results after the tests carried out using the following four criteria $\left(f_{1}-\right.$ Active power, $f_{2}-$ Lifespan, $f_{3}$ - Cost price, $f_{4}-$ Apparent power):

Weighting factors:

\begin{tabular}{|l|l|l|l|l|}
\hline & $\mathrm{w}_{1}$ & $\mathrm{w}_{2}$ & $\mathrm{w}_{3}$ & $\mathrm{w}_{4}$ \\
\hline Entropy & 0.109 & 0.062 & 0.322 & 0.100 \\
\hline CRITIC & 0.182779 & 0.276690 & 0.211101 & 0.174057 \\
\hline FANMA & 0.063 & 0.243 & 0.214 & 0.299 \\
\hline
\end{tabular}


(JPMNT) Journal of Process Management - New Technologies, International Vol. 1, No.4, 2013.

Comparison of the analysis methods SAW and CP using four criteria:

\begin{tabular}{|c|c|c|c|c|c|c|c|c|c|c|c|c|}
\hline \multirow[t]{2}{*}{ Method } & \multirow{2}{*}{$\begin{array}{ll}\text { Weight } & \text { of } \\
\text { criterion } & \end{array}$} & \multicolumn{11}{|c|}{ Bulbs } \\
\hline & & $A_{1}$ & $\mathbf{A}_{2}$ & $\mathbf{A}_{3}$ & $\mathbf{A}_{4}$ & $\mathbf{A}_{5}$ & $\mathbf{A}_{6}$ & $\mathbf{A}_{7}$ & $\mathbf{A}_{8}$ & $\mathbf{A}_{9}$ & $\mathbf{A}_{10}$ & $\mathbf{A}_{11}$ \\
\hline \multirow[t]{3}{*}{$\underline{\text { SAW }}$} & Entropy & 8 & 5 & 4 & 10 & 9 & 3 & 7 & 11 & 2 & $\underline{1}$ & 6 \\
\hline & CRITIC & 7 & 8 & 4 & 9 & 10 & 3 & 11 & 5 & 2 & $\underline{1}$ & 6 \\
\hline & FANMA & 8 & 6 & 4 & 10 & 9 & 3 & 11 & 7 & 2 & $\underline{1}$ & 5 \\
\hline \multirow[t]{3}{*}{$\underline{\mathrm{CP}}$} & Entropy & 8 & 5 & 4 & 10 & 9 & 2 & 11 & 7 & 3 & $\underline{1}$ & 6 \\
\hline & CRITIC & 6 & 10 & 4 & 7 & 11 & 3 & 9 & 5 & 2 & $\underline{1}$ & 8 \\
\hline & FANMA & 8 & 7 & 4 & 10 & 9 & 3 & 11 & 6 & 2 & $\underline{1}$ & 5 \\
\hline
\end{tabular}

V) The results after the tests carried out using the following three criteria $\left(f_{1}-\right.$ Active power, $f_{2}-$ Lifespan, $\mathrm{f}_{3}-$ Cost price)

Weighting factors:

\begin{tabular}{|l|l|l|l|}
\hline & $\mathrm{w}_{1}$ & $\mathrm{w}_{2}$ & $\mathrm{w}_{3}$ \\
\hline Entropy & 0.222 & 0.125 & 0.653 \\
\hline CRITIC & 0.351 & 0.365 & 0.284 \\
\hline FANMA & 0.176 & 0.229 & 0.594 \\
\hline
\end{tabular}

Comparison of the analysis methods SAW and CP using three criteria:

\begin{tabular}{|c|c|c|c|c|c|c|c|c|c|c|c|c|}
\hline \multirow[t]{2}{*}{ Method } & \multirow{2}{*}{$\begin{array}{ll}\text { Weight } & \text { of } \\
\text { criterion } & \end{array}$} & \multicolumn{11}{|c|}{ Bulbs } \\
\hline & & $\overline{A_{1}}$ & $\mathbf{A}_{2}$ & $\mathbf{A}_{3}$ & $\mathbf{A}_{4}$ & $\mathbf{A}_{5}$ & $\overline{A_{6}}$ & $\mathbf{A}_{7}$ & $\mathbf{A}_{8}$ & $\mathbf{A}_{9}$ & $\mathbf{A}_{10}$ & $\mathbf{A}_{11}$ \\
\hline \multirow[t]{3}{*}{$\underline{\text { SAW }}$} & Entropy & 7 & 6 & 4 & 10 & 9 & 3 & 11 & 8 & 2 & $\underline{1}$ & 5 \\
\hline & CRITIC & 7 & 8 & 4 & 9 & 10 & 3 & 11 & 6 & 2 & $\underline{1}$ & 5 \\
\hline & FANMA & 7 & 6 & 5 & 10 & 9 & 3 & 11 & 8 & 2 & $\underline{1}$ & 4 \\
\hline \multirow[t]{3}{*}{$\underline{\mathbf{C P}}$} & Entropy & 7 & 6 & 3 & 10 & 9 & 2 & 11 & 8 & 4 & $\underline{1}$ & 5 \\
\hline & CRITIC & 6 & 10 & 4 & 8 & 11 & 3 & 9 & 5 & $\underline{1}$ & 2 & 7 \\
\hline & FANMA & 6 & 7 & 4 & 10 & 9 & 3 & 11 & 8 & 2 & $\underline{1}$ & 5 \\
\hline
\end{tabular}




\section{CONCLUSION}

Method of multiple criteria decision and analyzes have become indispensable in planning, management and operational management of any life domain. With the use of computers and various software packages, can to solve the given problem_multi-criteria analysis in a relatively short period of time and for a relatively easy way. The main objective of this study was to determine the best and optimal solution when choosing compact fluorescent bulbs and all this by the methods of multi-criteria decision making, specifically in this case the methods SAW and CP, or the methods of compromise programming. Consistent application of these methods for a pre-determined weight of criteria we came to a very similar and the approximate solutions from which we can conclude that the bulb $\mathrm{A}_{9}$ stands out from others in that it gives the best result.

Bulb $A_{10}$ gives the best result when you not take into consideration the brightness. On the other hand, worst results that match your criteria have a bulbs $\mathrm{A}_{4}, \mathrm{~A}_{5}$ and $\mathrm{A}_{7}$.

\section{REFERENCES}

[1] Opricović, S. (1986) Višekriterijumska optimizacija, Naučna knjiga, Belgrade

[2] Nikolić, M. (2009) Metode odlučivanja, Tehnički Fakultet "Mihajlo Pupin", Zrenjanin

[3] Srđević B.,, Medeiros Y.D.P., Faria, A.S., Schaer, M., Objektivno vrednovanje kriterijuma performanse sistema akumulacija. Vodoprivreda, 35, 163-176, Novi Sad, 2003.

[4] Diakoulaki, D., Mavrotas, G., Papayannakis L., Determining objective weights in multiple criteria problems: the CRITIC method. Computers and Operations Research, 22, 763$770,1995$.

[5] Srđević B., Nepristrasna ocena značaja kriterijuma u višekriterijumskoj optimizaciji. Vodoprivreda, 37, 53-58, 2005.

[6] Hwang C.L., Yoon K.S.: Multiple attribute decision making: methods and applications, Springer, Berlin, 1981.

[7] Zeleny, M. (1982) Multiple citeria decision making, McGraw-Hill Book Company, New York

[8] M. Vujičić, S. Vasović, M. Radojičić, J. Vesić Vasović, Z. Nešić, Multi-criteria approach to optimization of optimal feeder conductor size, Metalurgia international, ISSN 1582-2214, vol. XVII, no. 4 (2012), str. 47-52.

[9] M. Žižović, N. Damljanović, M.Vujičić, N. Jakšić, The optimal choice of light bulbs on the serbian market. Metalurgia international, ISSN 1582-2214, vol. XVIII, no. 8 (2013), str. 170172. 